\title{
Risperidone Versus Risperidone Plus Sodium Valproate for Treatment of Bipolar Disorders: A Randomized, Double-Blind Clinical-Trial
}

\author{
S. Mohammad Moosavi ${ }^{1}$, Mahshid Ahmadi ${ }^{2} \&$ Mani B. Monajemi ${ }^{3}$ \\ ${ }^{1}$ Department of Psychiatry, Mazandaran University of Medical Science. Psychiatry and Behavioral Science \\ Research Center, Sari, Iran \\ ${ }^{2}$ Department of Community Medicine, Medical College, Mazandaran University of Medical Science, Sari, Iran \\ ${ }^{3}$ Department of Clinical Psychology and Mental Health Sciences, University of Tehran, Tehran, Iran \\ Correspondence: S. Mohammad Moosavi, Department of Psychiatry, Mazandaran University of Medical Science. \\ Psychiatry and Behavioral Science Research Center, Sari, Iran. E-mail: smhdmoosavi@yahoo.com
}

Received: April 25, 2014 Accepted: June 3, 2014 Online Published: July 29, 2014

doi:10.5539/gjhs.v6n6p163 URL: http://dx.doi.org/10.5539/gjhs.v6n6p163

\begin{abstract}
Objective: This study compared the efficacy of risperidone monotherapy with risperidone plus valproate in bipolar I disorder, manic phase. Some studies showed the efficacy of risperidone monotherapy in the treatment of bipolar disorder, so we examined this effectiveness in this clinical-trial study.

Method: This 7-week, randomized, single-blind study included 48 bipolar I inpatients manic phase without psychotic features divided in risperidone group $(n=23)$ and risperidone plus sodium valproate group $(n=25)$. According to clinical symptoms, 3 categories: complete remission, partial remission and no remission were mentioned in weekly follow-up. Remission rate compared with survival analysis.

Results: The results showed a significant difference in remission rate between risperidone monotherapy and risperidone plus sodium valproate at the $1^{\text {st }}, 2^{\text {nd }}$ and the $3^{\text {rd }}$ week $(p=0.012,0.023,0.027$ respectively), It means the remission rate in risperidone plus valproate group was higher in the first three weeks, but at the end of the seventh week, the difference was not statistically significant. There was no significant difference between the two groups in the development of adverse effects.
\end{abstract}

Conclusions: Risperidone can be effective and well tolerated in both acute manic episodes of bipolar mood disorders.

Keywords: bipolar disorder, risperidone, sodium valproate

\section{Introduction}

First Generation Antipsychotics (FGA) had been used for the treatment of acute mania. Development of extrapyramidal side effects (EPS) and tardive dyskinesia (TD) is the major limitation of using these drugs. Second Generation Antipsychotics (SGA) have been increasingly used for management of acute mania since the year 2000. SGAs are shown to induce less extrapyramidal side effects in comparison with FGA (Perlis et al., 2006). Practice guidelines recommend initiating treatment with either a mood-stabilizing agent or SGA followed by therapy (Hirschfeld et al., 2002; Suppes et al., 2005). Randomized, placebo-controlled trials have demonstrated efficacy of SGA (olanzapine, risperidone, quetiapine, ziprasidone, aripiprazole), for treatment of acute manic phase of bipolar disorders (Tohen et al., 2000; Smulevich et al., 2005). Risperidone (average dose $4.1 \mathrm{mg}$ ) produced response rates of $43 \%$ in comparison with $24 \%$ on placebo (Hirschfeld et al., 2004). In another trial, risperidone with mean dose of $5.6 \mathrm{mg}$ produced response in $73 \%$ of patients in comparison with $36 \%$ observed in the placebo group (6). In a 12-week, single-blind, placebo-controlled trial for acute mania, risperidone ( 1 to $6 \mathrm{mg} / \mathrm{d}$ ) produced a response rate of $48 \%$, similar to the response rate of $47 \%$ by haloperidol (2 to $12 \mathrm{mg} / \mathrm{d}$ ) (Smulevich et al., 2005). Sachs et al. assessed the efficacy and safety of risperidone as an adjunctive agent to mood stabilizers in the treatment of acute mania. In a randomized, double-blind trial including patients with bipolar disorder (manic or mixed phase) who were inadequately responding to mood stabilizer (MS), risperidone, haloperidol or placebo was added. The study demonstrated risperidone plus a mood stabilizer was more effective than a mood stabilizer alone, and as effective as haloperidol plus a mood stabilizer (Sachs et al., 2002). Yatham et al. examined the efficacy of combination of MS with risperidone and showed that risperidone 
was more effective than placebo when combined with lithium or divalproex in acute mania (Yatham et al., 2003). Bipolar mood disorder is a lifetime disorder that has a recurrence rate of as high as $90 \%$. Most studies about treatment of bipolar disorders have a short duration (for example 3 weeks). Therefore, studies evaluating maintenance phase treatment may better predict efficacy of a drug (Gajwani et al., 2006). We compared the effects of risperidone monotherapy with risperidone plus sodium valproate in a 7-week randomized single blind study for assessment of their tolerability, safety and efficacy in improvement of treatment during bipolar therapy.

\section{Materials and Methods}

The study was a 7-week- randomized double-blind - single centered clinical- trial involving manic patients conducted at Sari Psychiatric hospital (Mazandaran province). The recruitment began in 2012 and ended in 2013. Prior to randomization, eligibility was assessed and medical and psychiatric examinations were completed.

Patients with a diagnosis of bipolar I disorder (manic phase without psychotic features) based on DSM-IV-TR criteria were included. Substance dependency, comorbidity with other psychiatric disorders, general medical diseases (hepatic, kidney, respiratory, etc.), age older than 20 or less than 60 and pregnancy were exclusion criteria. Seventy five patients were selected. Informed consent was obtained from first-degree relatives. Ten of them refused to participate. Blood samples were obtained from all patients for measurement of FBS (Fasting Blood Sugar), CBC (Complete Blood Count), Aminotransferase (Liver Function Test), Serum creatinine, lipid profile and electrolytes. All subjects were examined through urine drug screening. The patients were then randomly divided in two groups (group 1 received risperidone versus group 2 received risperidone plus sodium valproate). Eleven patients discharged by attending and 6 of subjects discharged by family members and all of these subjects were excluded.

Demographic data and the numbers of prior hospitalization were registered. Patients in group $1(n=23)$ received risperidone with a starting dose of 6-8 $\mathrm{mg}$ per day in divided dose. Patients in group $2(\mathrm{n}=25)$ received sodium valproate 800-1200 mg per day in divided dose plus risperidone with the same dose of group 1. Clonazepam (2-3 mg per day) and trihexyphenidyl (4-6 mg pre day) started in divided dose in both groups. None of subjects received Electro Convulsive Therapy (ECT). All subjects were evaluated on the $7^{\text {th }}, 14^{\text {th }}, 21$ th and $49^{\text {th }}$ days after their admission based on DSM-IVTR clinically. Patients in each group were divided in three response groups based on DSM-IV-TR criteria for bipolar disorder (manic episode without psychotic features):

Full remission: without DSM-IV-TR criteria

Partial remission: one or two criteria

No remission: three or more criteria or no change

At the end, considering a $\mathrm{P}$ value of $\leq 0.05$ as significant, the data were analyzed by survival tests and Chi-square through SPSS 17.

\section{Results}

There was no significant difference between two groups in baseline characteristics (Table 1). The results showed a significantly more remission rate in the second group at the end of $1^{\text {st }}, 2^{\text {nd }}$ and the $3^{\text {rd }}$ week (Table 2). Furthermore, at the end of the seventh week, there was no statistically significant difference when comparing the two groups with regard to remission (Table 2).

All patients in both groups has been received prophylactic anticholinergic drugs (trihexyphenidyl) $6 \mathrm{mg}$ daily in divided dose) and benzodiazepine (clonazepam) 2-3 mg daily. Adverse events were reported by $7(30.4 \%)$ and $8(32.0 \%)$ of patients in risperidone alone and, risperidone plus sodium valproate groups, respectively. In both groups, the most commonly reported adverse effects were: somnolence, tremor, dizziness and constipation. None of the participants were excluded for adverse events. No clinically significant changes in vital signs were noted in both groups. Incidence of adverse events was similar in both groups and there was no significant difference between the two groups in the development of adverse effects. 
Table1. Demographic data in risperidone and risperidone plus valproate groups

\begin{tabular}{lll}
\hline & $\begin{array}{l}\text { Group 1 } \\
\text { (Risperidone) }\end{array}$ & $\begin{array}{l}\text { Group 2 } \\
\text { (Risperidone+ valproate) }\end{array}$ \\
\hline $\mathbf{N}$ & 23 & 25 \\
Female/Male & $7 / 16$ & $7 / 18$ \\
Age(mean+/- S.D) & $26 \pm 1.3$ & $24 \pm 1.1$ \\
First time hospitalization & 8 & 10 \\
History of prior hospitalization & 15 & 15 \\
\hline
\end{tabular}

$(\mathrm{P}>0.05)$

Table 2. Comparing the rates of complete remission, partial remission and no remission between two groups at $1^{\text {st }}, 2^{\text {nd }}, 3^{\text {rd }}$ and $7^{\text {th }}$ week of treatment

\begin{tabular}{lllll}
\hline & & $\begin{array}{l}\text { group 1 } \\
\text { (Risperidone) } \\
\text { n (\%) }\end{array}$ & $\begin{array}{l}\text { group 2 } \\
\text { (Risperidone+ } \\
\text { valproate) n (\%) }\end{array}$ & P \\
\hline Complete & Week 1 & $7(30.4 \%)$ & $10(40.0 \%)$ & $\mathbf{0 . 0 1 2}$ \\
Remission & Week 2 & $12(52.2 \%)$ & $15(60.0 \%)$ & $\mathbf{0 . 0 2 3}$ \\
& Week 3 & $20(86.9 \%)$ & $22(88.0 \%)$ & $\mathbf{0 . 0 2 7}$ \\
\hline Partial & Week 7 & $21(91.3 \%)$ & $23(92.0 \%)$ & $\mathbf{0 . 0 9 8}$ \\
Remission & Week 1 & $9(39.1 \%)$ & $9(36.0 \%)$ & $\mathbf{0 . 0 1}$ \\
& Week 2 & $5(21.7 \%)$ & $5(20.0 \%)$ & $\mathbf{0 . 0 1 8}$ \\
\hline Week 3 & $0(0.0 \%)$ & $0(0.0 \%)$ & - \\
& Week 7 & $2(8.7 \%)$ & $2(8.7 \%)$ & $\mathbf{0 . 0 7 8}$ \\
\hline
\end{tabular}

\section{Discussion}

The results of this study showed a significant difference in remission rate between risperidone monotherapy and risperidone plus sodium valproate at the $1^{\text {st }}, 2^{\text {nd }}$ and the $3^{\text {rd }}$ week (risperidone plus sodium valproate was superior), but at the end of the seventh week, the difference was not statistically significant. None of the participants were dropped out for adverse events. There was no significant difference between the two groups in the development of adverse effects. Our finding was compatible with Schreiner et al. and Smulevich et al. in demonstrating that risperidone alone can be a tolerable and effective choice in the treatment of bipolar mood disorders (Smulevich et al., 2005; Schreiner, 2006).

Poor adherence to medication during maintenance treatment of bipolar mood disorder is common and exposing patients to the higher risk of relapses, rehospitalization and other negative consequences. Long-acting injectable antipsychotic medications have been used to improve treatment outcome during bipolar maintenance treatment. However, risk of extrapyramidal side effects, tardive dyskinesia, and exacerbation of depressive symptoms are some important limitations to the long-term use of depot FGA in patients with bipolar disorder (18). In contrast, SGA have fewer extrapyramidal side effects and have been better tolerated. Some trials have shown that risperidone was effective and well tolerated in both treatment of acute manic episodes and the maintenance therapy (Smulevich et al., 2005; Schreiner, 2006). Recent data suggest that risperidone can be used effectively either in monotherapy or in combination with a mood stabilizer (Schreiner, 2006). Risperidone long-acting injection (RLAI) is the first long-acting preparation of an SGA introduced into clinical practice (De la Gándara et 
al., 2009). RLAI have benefits of SGA accompanied with long duration of action and is best for long-term treatment adherence of patients with schizophrenia. De la Gándara et al studied the experiences with injectable long-acting risperidone and have shown that RLAI was well tolerated in the patients with schizophrenia and the overall impression of patients, primary caregivers and relatives to RLAI was positive (De la Gándara et al., 2009).

There are some limitations to this trial. For ethical reasons, patients were permitted to leave the trial. Eleven patients discharged by attending and 6 of subjects discharged by family members before completing the trial and all of these subjects were excluded. Serum levels of applied medication were not measured in these trials, so assessment of treatment adherence was relatively difficult. However all patients were admitted and all drugs have been swallowed under the supervision of a trained nurse.

This study allowed enrollment of only non-psychotic patients and more severely ill manic patients with psychotic features excluded from the study. Generalization is limited because of exclusion of psychotic patients and individuals with psychiatric co-morbidities

This study does not indicate that risperidone is a mood stabilizer, but support the need for additional longer-term studies for better estimation of the effectiveness of different medications and the long-term outcomes in patients with bipolar disorders. Risk factors and drug costs should be considered when prescribing a medication for a patient (Patel et al., 2005).

\section{Authors' Contributions}

SMM conceived and designed the study, collected the clinical data, interpreted them and helped to draft the manuscript. MA participated in the evaluating and statistical analysis and revised the manuscript. SF re-analyzed the clinical data and revised the manuscript. MM interpreted the clinical data, revised the manuscript and helped to draft the manuscript. All authors read and approved the final manuscript.

\section{Acknowledgements}

With grateful thanks to all participants.

\section{Declaration of Interest}

None.

\section{References}

Bobo, W. V., \& Shelton, R. C. (2010). Risperidone long-acting injectable (Risperdal Consta ${ }^{\circledR}$ ) for maintenance treatment in patients with bipolar disorder. http://dx.doi.org/10.1586/ern.10.143

Bowden, C. L., Grunze, H., Mullen, J., Brecher, M., Paulsson, B., Jones, M., ... Svensson, K. (2005). A randomized, double-blind, placebo-controlled efficacy and safety study of quetiapine or lithium as monotherapy for mania in bipolar disorder. Journal of Clinical Psychiatry, 66(1), 111-121. http://dx.doi.org/10.4088/JCP.v66n0116

De la Gándara, J., San Molina, L., Rubio, G., Rodriguez-Morales, A., Hidalgo Borrajo, R., \& Burón, J. A. (2009). Experience with injectable long-acting risperidone in long-term therapy after an acute episode of schizophrenia: the SPHERE Study. Expert Rev Neurother, 9(10), 1463-1474. http://dx.doi.org/10.1586/ern.09.96

Gajwani, P., Kemp, D. E., Muzina, D. J., Xia, G., Gao, K., \& Calabrese, J. R. (2006). Acute treatment of mania: an update on new medications. Current psychiatry reports, 8(6), 504-509. http://dx.doi.org/10.1007/s11920-006-0058-3

Hirschfeld, R. M., Bowden, C. L., Gitlin, M. J., Keck, P. E., Perlis, R. H., Suppes, T., ... \& Wagner, K. D. (2003). Practice guideline for the treatment of patients with bipolar disorder (revision). FOCUS: The Journal of Lifelong Learning in Psychiatry, 1(1), 64-110.

Hirschfeld, R. M., Keck, P. E., Kramer, M., Karcher, K., Canuso, C., Eerdekens, M., \& Grossman, F. (2004). Rapid antimanic effect of risperidone monotherapy: a 3-week multicenter, double-blind, placebo-controlled trial. American Journal of Psychiatry, 161(6), 1057-1065. http://dx.doi.org/10.1176/appi.ajp.161.6.1057

Keck, P. E., Marcus, R., Tourkodimitris, S., Ali, M., Liebeskind, A., Saha, A., ... Aripiprazole Study Group. (2003). A placebo-controlled, double-blind study of the efficacy and safety of aripiprazole in patients with acute bipolar mania. American Journal of Psychiatry, 160(9), 1651-1658. http://dx.doi.org/10.1176/appi.ajp.160.9.1651 
Keck, P. E., Versiani, M., Potkin, S., West, S. A., Giller, E., \& Ice, K. (2003). Ziprasidone in the treatment of acute bipolar mania: a three-week, placebo-controlled, double-blind, randomized trial. American Journal of Psychiatry, 160(4), 741-748.

Khanna, S., Vieta, E., Lyons, B., Grossman, F., Eerdekens, M., \& Kramer, M. (2005). Risperidone in the treatment of acute mania Double-blind, placebo-controlled study. The British Journal of Psychiatry, 187(3), 229-234. http://dx.doi.org/10.1192/bjp.187.3.229

McIntyre, R. S., Brecher, M., Paulsson, B., Huizar, K., \& Mullen, J. (2005). Quetiapine or haloperidol as monotherapy for bipolar mania-a 12-week, double-blind, randomised, parallel-group, placebo-controlled trial. European Neuropsychopharmacology, 15(5), 573-585.

Patel, N. C., Crismon, M. L., \& Pondrom, M. (2005). Rehospitalization rates of patients with bipolar disorder discharged on a mood stabilizer versus a mood stabilizer plus an atypical or typical antipsychotic. $J$ Behav Health Serv Res, 32(4), 438-45. http://dx.doi.org/10.1097/00075484-200510000-00009

Perlis, R. H., Welge, J. A., Vornik, L. A., Hirschfeld, R. M., \& Keck Jr, P. E. (2006). Atypical antipsychotics in the treatment of mania: a meta-analysis of randomized, placebo-controlled trials. J Clin Psychiatry, 67(4), 509-516. http://dx.doi.org/10.1136/ebmh.10.1.11

Potkin, S. G., Keck Jr, P. E., Segal, S., Ice, K., \& English, P. (2005). Ziprasidone in acute bipolar mania: a 21-day randomized, double-blind, placebo-controlled replication trial. Journal of Clinical Psychopharmacology, 25(4), 301-310. http://dx.doi.org/10.1097/01.jcp.0000169068.34322.70

Sachs, G. S., Grossman, F., Ghaemi, S. N., Okamoto, A., \& Bowden, C. L. (2002). Combination of a mood stabilizer with risperidone or haloperidol for treatment of acute mania: a double-blind, placebo-controlled comparison of efficacy and safety. American Journal of Psychiatry, 159(7), 1146-1154. http://dx.doi.org/10.1176/appi.ajp.159.7.1146

Sachs, G., Sanchez, R., Marcus, R., Stock, E., Mcquade, R., Carson, W., ... \& Iwamoto, T. (2006). Aripiprazole in the treatment of acute manic or mixed episodes in patients with bipolar I disorder: a 3-week placebo-controlled study. Journal of Psychopharmacology, 20(4), 536-546. http://dx.doi.org/10.1177/0269881106059693

Schreiner, A. (2006). [Treatment of bipolar mania with risperidone]. Psychiatrische Praxis, 33, S12-7. http://dx.doi.org/10.1055/s-2005-867024

Smulevich, A. B., Khanna, S., Eerdekens, M., Karcher, K., Kramer, M., \& Grossman, F. (2005). Acute and continuation risperidone monotherapy in bipolar mania: a 3-week placebo-controlled trial followed by a 9-week double-blind trial of risperidone and haloperidol. European Neuropsychopharmacology, 15(1), 75-84. http://dx.doi.org/10.1016/j.euroneuro.2004.06.003

Suppes, T., Dennehy, E. B., Hirschfeld, R. M., Altshuler, L. L., Bowden, C. L., Calabrese, J. R., ... \& Swann, A. C. (2005). The Texas implementation of medication algorithms: update to the algorithms for treatment of bipolar I disorder. Journal of Clinical Psychiatry, 66(7), 870-886. http://dx.doi.org/10.4088/JCP.v66n0710

Tohen, M., Jacobs, T. G., Grundy, S. L., McElroy, S. L., Banov, M. C., Janicak, P. G., ... \& Breier, A. (2000). Efficacy of olanzapine in acute bipolar mania: a double-blind, placebo-controlled study. Archives of General Psychiatry, 57(9), 841-849. http://dx.doi.org/10.1001/archpsyc.57.9.841

Vieta, E., Mullen, J., Brecher, M., Paulsson, B., \& Jones, M. (2005). Quetiapine monotherapy for mania associated with bipolar disorder: combined analysis of two international, double-blind, randomised, placebo-controlled studies. Current Medical Research and Opinion ${ }^{\circledR}, 21(6), 923-934$.

Yatham, L. N., Grossman, F., Augustyns, I., Vieta, E., \& Ravindran, A. (2003). Mood stabilisers plus risperidone or placebo in the treatment of acute mania International, double-blind, randomised controlled trial. The British Journal of Psychiatry, 182(2), 141-147. http://dx.doi.org/10.1192/bjp.182.2.141

\section{Copyrights}

Copyright for this article is retained by the author(s), with first publication rights granted to the journal.

This is an open-access article distributed under the terms and conditions of the Creative Commons Attribution license (http://creativecommons.org/licenses/by/3.0/). 